\title{
Early responding to traumatic events ${ }^{\dagger}$
}

\author{
Jonathan I. Bisson
}

\author{
Summary \\ How to respond optimally following traumatic events remains \\ a Holy Grail. A number of early interventions lack evidence of \\ effect. Practical, pragmatic support provided in an empathic \\ manner is likely to be an appropriate initial response and \\ complement the high levels of resilience shown by \\ individuals exposed to traumatic events.
}

\section{Declaration of interest}

None.

\begin{abstract}
Jonathan I. Bisson is a professor at the Institute of Psychological Medicine and Clinical Neurosciences at Cardiff University and an honorary consultant psychiatrist. He leads the Traumatic Stress Research Group at Cardiff University.
\end{abstract}

The 22 July 2011 Norway terrorist attacks horrified the world. The nature of the traumatic experiences endured by those involved was extreme; even the most hardened critics of the post-traumatic stress disorder (PTSD) diagnosis would be likely to acknowledge that the experiences were severe enough to precipitate significant distress, if not disorder, in many of those present. Dyb and colleagues $^{1}$ interviewed survivors over 12 years old who were on Utøya Island at the time of the attacks, $4-5$ months later. The nature of the trauma, inclusion of two-thirds of the 490 survivors who were on the island at the time, along with the young age of the majority of those interviewed (mean 19.4 years) makes this study unique. The study confirmed the repeated finding that not all individuals exposed to extremely traumatic events develop PTSD. ${ }^{2}$ Indeed, the $11 \%$ prevalence of 'full PTSD' and $36 \%$ rate of 'partial PTSD' are lower than might be anticipated after such an extreme event and point to resilience among those involved. Various factors may contribute to this, including many that were not measured. Younger age has not been consistently found to be associated with lower rates of PTSD after traumatic events but high level of perceived social support, a key finding in this study, has been. ${ }^{3}$

\section{Early psychosocial response}

Dyb and colleagues' study raises the important yet still not fully resolved question of how to optimally respond from a psychosocial perspective following major traumatic events. The evidence has slowly moved forward over recent years but very early interventions remain evidence-informed rather than evidence-based. The notion of providing single-session preventive interventions for everyone involved has been dismissed as a result of evidence showing that single-session psychological debriefing, despite often being liked by recipients, is at best neutral and may even cause harm in some people. ${ }^{4,5}$ Subsequent attempts to develop multiple-session psychosocial interventions for everyone have also largely failed to show benefit over no formal intervention. ${ }^{6}$ The routine use of pharmacotherapy to temper the initial adrenergic response associated with the development of PTSD does not appear to be the answer. ${ }^{5}$

†See pp. 361-367, this issue.
The prospect of offering absolutely nothing, although arguably as evidence-based as anything, is not an attractive option to many people and does not address the repeated finding of perceived high levels of social support being protective. Many guidelines caution against doing nothing shortly after traumatic events, recommending the delivery of supportive, practical and pragmatic input in a supportive and empathic manner but avoidance of formal clinical interventions. ${ }^{5,7,8}$ Such approaches do not resemble psychological treatments, in contrast to most of the early interventions that have been subjected to randomised controlled trials. They are psychosocial with key social elements that address people's basic needs, such as housing, finances and nutrition.

Innovative work has moved the field away from the medicalisation of something that should not be medicalised, not in the majority, anyway. By extrapolating findings from related fields of research, five early intervention principles have been proposed: promoting a sense of safety, calming, a sense of selfand community-efficacy, connectedness and hope. ${ }^{9}$ These principles, along with human and community resiliency, now underpin best practice guidance to early intervention following traumatic events ${ }^{7,8,10}$ and have contributed to the re-emergence of psychological first aid.

\section{Psychological first aid}

First described in the 1950s, the principles of psychological first aid are increasingly advocated and used in the provision of early psychosocial intervention following traumatic events. Designed to be provided by trained lay people, the Inter-Agency Standing Committee described psychological first aid as 'a description of a humane, supportive response to a fellow human being who is suffering and who may need support.' ${ }^{11}$ It is an approach that aims to address the psychosocial needs of those involved in major traumatic events. Key components include: active listening with the provision of an opportunity to talk while respecting the desire not to talk about their experience; assessing basic and physical needs and ensuring these are met; promoting positive coping mechanisms; supportive advice and linking people with sources of support, including family and friends; encouraging participation in normal daily routines; identification of those who need further help and facilitating referral to more specialist services when indicated.

Despite its burgeoning popularity, psychological first aid remains a non-evidence-based intervention ${ }^{12}$ and we continue to await definitive evidence that it is appropriate. (The same can be said of emerging approaches using peer support. ${ }^{13}$ ) Given the current evidence, considered use of the principles of psychological 
first aid, as part of a well-coordinated response, appears to be an appropriate way to provide early psychosocial support.

Provision of psychosocial care following major traumatic events needs to be integrated with other services and part of the overall traumatic event response plan. Pre-planning, good coordination and adequate training (something that is often neglected until disaster strikes) are key. Ongoing planning will also be required as major traumatic events unfold; each will have unique characteristics and require a modified response.

\section{Evidence-based treatments}

The better news is that we do have evidence that specific treatments can be effective for established disorders following traumatic events. Trauma-focused cognitive-behavioural therapy has a good evidence base for DSM-IV acute stress disorder ${ }^{14}$ from 2 weeks after a trauma and for PTSD from 1 month. ${ }^{6}$ For PTSD of 3 months duration or longer, the evidence base is much stronger for trauma-focused cognitive-behavioural therapy and also strong for eye movement desensitisation and reprocessing. ${ }^{5,15}$ Recent reviews have consistently shown small positive benefits for selective serotonin reuptake inhibitors in the treatment of PTSD, although when considered individually some (e.g. paroxetine and fluoxetine) have a better evidence base than others. ${ }^{15}$ Venlafaxine has a similar evidence base for the treatment of PTSD. ${ }^{15}$

\section{Conclusions}

There remain many challenges to be addressed in preventing PTSD and other mental disorders following traumatic events. Key messages from the current evidence are that very early formal psychological and pharmacological interventions have not been shown to work and that practical, pragmatic support provided in an empathic manner is an appropriate initial response. Early detection and appropriate referral of those with more significant difficulties is important as there are a number of effective treatments available for PTSD and other disorders that occur following traumatic events. Thankfully, a large percentage of individuals are resilient after trauma ${ }^{16}$ and, although we do not know how to prevent disorder, we know what we can do to facilitate recovery and resilience by increasing access to protective factors and seeking to remove or mitigate further hazards.

Jonathan I. Bisson, BM, FRCPsych, DipClinPsychotherapy, DM, Institute of Psychological Medicine and Clinical Neurosciences, Cardiff University, Hadyn Ellis Building, Maindy Road, Cathays, Cardiff CF24 4HQ, UK. Email: bissonji@cf.ac.uk

First received 6 Oct 2013, final revision 23 Feb 2014, accepted 6 Mar 2014

\section{References}

1 Dyb G, Jensen TK, Nygaard E, Ekeberg $\oslash$, Diseth TH, Wenzel-Larsen T, et al. Post-traumatic stress reactions in survivors of the 2011 massacre on Utøya Island, Norway. Br J Psychiatry 2014; 204: 361-7.

2 Kessler RC, Berglund P, Demler O, Jin R, Merikangas KR, Walters EE. Prevalence, severity, and comorbidity of 12-month DSMIV disorders in the National Comorbidity Survey Replication. Arch Gen Psychiatry 2005; 62: 617-27.

3 Brewin CR, Andrews B, Valentine JD. Meta-analysis of risk factors for posttraumatic stress disorder in trauma-exposed adults. J Consult Clin Psychol 2000; 68: 748-66.

4 Rose S, Bisson J, Churchill R, Wessely S. Psychological debriefing for preventing post traumatic stress disorder (PTSD). Cochrane Database syst Rev 2009; 1: CD000560.

5 National Collaborating Centre for Mental Health. Post-Traumatic Stress Disorder: The Management of PTSD in Adults and Children in Primary and Secondary Care. Gaskell, 2005.

6 Roberts N, Kitchiner N, Kenardy J, Bisson Jl. Systematic review and meta-analysis of multiple session early interventions for traumatic events. Am J Psychiatry 2009; 166: 293-301.

7 Bisson Jl, Tavakoly B, Witteveen AB, Ajdukovic D, Jehel L, Johansen VJ, et al. TENTS guidelines: development of post-disaster psychosocial care guidelines through a Delphi process. Br J Psychiatry 2010; 196: 69-74.

8 North Atlantic Treaty Organisation (NATO). Psychosocial Care for People Affected by Disasters and Major Incidents: A Model for Designing, Delivering and Managing Psychosocial Services for People involved in Major Incidents, Conflict, Disasters and Terrorism. Annex 1 to EAPC(JMC)N(2008)0038. NATO, 2009.

9 Hobfoll SE, Watson P, Bell CC, Bryant RA, Brymer MJ, Friedman MJ, et al. Five essential elements of immediate and mid-term mass trauma intervention: empirical evidence. Psychiatry 2007; 70: 283-315.

10 Department of Health. Planning for the Psychosocial and Mental Health Care of People Affected by Major Incidents and Disasters: Interim National Strategic Guidance. Department of Health, 2009.

11 Inter-Agency Standing Committee (IASC). IASC Guidelines on Mental Health and Psychosocial Input Support in Emergency Situations. IASC, 2007

12 Bisson Jl, Lewis C. Systematic Review of Psychological First Aid. World Health Organization, 2009.

13 Australian Centre for Posttraumatic Mental Health. Development of Guidelines on Peer Support using the Delphi Methodology. ACPMH, 2011 (http://www.acpmh.unimelb.edu.au/).

14 American Psychiatric Association. Diagnostic and Statistical Manual of Mental Disorder (4th edn) (DSM-IV). APA, 1994.

15 Jonas DE, Cusack K, Forneris CA, Wilkins TM, Sonis J, Middleton JL, et al. Psychological and Pharmacological Treatments for Adults with Posttraumatic Stress Disorder (PTSD). Comparative Effectiveness Review 92. Agency for Healthcare Research and Quality, 2013.

16 Norris FH, Tracy M, Galea S. Looking for resilience: understanding the longitudinal trajectories of responses to stress. Soc Sci Med 2009; 68 2190-8. 